\title{
Circulating concentrations of GLP-1 are associated with coronary atherosclerosis in humans
}

\author{
Katja Piotrowski ${ }^{2}$, Melanie Becker ${ }^{2}$, Julia Zugwurst ${ }^{2}$, Ingeborg Biller-Friedmann², Gerald Spoettl ${ }^{2}$, Martin Greif ${ }^{3}$, \\ Alexander W Leber ${ }^{3}$, Alexander Becker ${ }^{3}$, Rüdiger P Laubender ${ }^{4}$, Corinna Lebherz', Burkhard Goeke², \\ Nikolaus Marx', Klaus G Parhofer ${ }^{2}$ and Michael Lehrke ${ }^{1 *}$
}

\begin{abstract}
Background: GLP-1 is an incretine hormone which gets secreted from intestinal L-cells in response to nutritional stimuli leading to pancreatic insulin secretion and suppression of glucagon release. GLP-1 further inhibits gastric motility and reduces appetite which in conjunction improves postprandial glucose metabolism. Additional vasoprotective effects have been described for GLP-1 in experimental models. Despite these vasoprotective actions, associations between endogenous levels of GLP-1 and cardiovascular disease have yet not been investigated in humans which was the aim of the present study.
\end{abstract}

Methods: GLP-1 serum levels were assessed in a cohort of 303 patients receiving coronary CT-angiography due to typical or atypical chest pain.

Results: GLP-1 was found to be positively associated with total coronary plaque burden in a fully adjusted model containing age, sex, BMl, hypertension, diabetes mellitus, smoking, triglycerides, LDL-C (low density lipoprotein cholesterol), hsCRP (high-sensitive C-reactive protein), and eGFR (estimated glomerular filtration rate) (OR: 2.53 (95\% Cl: $1.12-6.08 ; p=0.03)$.

Conclusion: Circulating GLP-1 was found to be positivity associated with coronary atherosclerosis in humans. The clinical relevance of this observation needs further investigations.

Keywords: GLP-1, Atherosclerosis, Coronary CT angiography

\section{Background}

Hyperglycemia and insulin resistance are determinants of cardiovascular risk with fasting blood glucose and insulin concentrations being directly predictive for future cardiovascular events [1,2]. Nevertheless, intensified glucose lowering therapies have failed to substantially lower cardiovascular risk in diabetic patients [3].

Recent reports suggest GLP-1 modulating drugs to hold beneficial cardiovascular characteristics [4]. GLP-1 is an incretine hormone which is secreted from intestinal L-cells in response to nutritional stimuli. Circulating GLP-1 binds to its receptor expressed on pancreatic beta-cells leading to glucose dependent insulin secretion. In addition, GLP-1 suppresses glucagon release from pancreatic alpha cells,

\footnotetext{
* Correspondence: mlehrke@ukaachen.de

'Department of Internal Medicine I, University Hospital Aachen,

Pauwelsstraße 30, 52074, Aachen, Germany

Full list of author information is available at the end of the article
}

impairs gastric motility and reduces appetite which in conjunction improves postprandial glucose metabolism [5]. Furthermore, anti-inflammatory and atheroprotective effects have been described for GLP-1 which extends to cardioprotection during acute myocardial infarction [4]. Relevance of endogenous GLP-1 serum levels for cardiovascular risk prediction in humans has so far not been considered. Impaired GLP-1 secretion has been reported in obese and diabetic subjects in some studies [6-8]. This was however not confirmed in a recent meta-analysis which reported increased GLP-1 serum concentrations in diabetic individuals [9]. Similarly, others have found elevated GLP1 serum levels in obesity and insulin resistance [10]. This study aimed to assess associations between GLP-1 serum levels and coronary atherosclerosis in humans. 


\section{Methods}

Blood samples were collected randomly (independent of fasting) in 303 consecutive patients who underwent DSCTcoronary angiography for exclusion of coronary artery stenosis due to stable typical or atypical chest pain. Detailed information regarding recruitment, baseline characteristics, dual-source multi-slice CT-coronary angiography, dual-source CT image analysis, pericardial fat assessment, and laboratory procedures have previously been published and are summarized in Table 1. Briefly, the coronary tree was segmented according to the suggestions of the AHA into a 15 segment model. Each segment was further divided into a proximal and a distal segment. Each segment was then classified as containing or not containing a plaque. Based on the number of diseased segments a plaque score was calculated. Adequate image quality for evaluation of coronary plaques was obtained in 281 of 303 patients. The study protocol was approved by the Ethics Committee of the Ludwig-Maximilians-University Munich.

\section{Protein chemistry}

GLP-1 serum levels were determined using chemiluminescent enzyme-linked immunosorbent assay (ELISA) after ethanol extraction from 300 ul of plasma. Antibodies were purchased from Bioporto (Gentofte, Denmark). The primary antibody was HYB 147-06, which reacts with the amidated C-terminus of GLP-1 (1-36amide), GLP-1 (7-36amide) and GLP-1 (9-36amide). The detection antibody was biotinylated HYB 147-12 which reacts to the mid-molecular epitope of GLP-1. The Intra-Assay and Inter-Assay CV were $7.29 \%$ and $12.79 \%$. The assay did provide a linear standard curve $(R=0.98)$ with the lowest standard being used at $1.5 \mathrm{pM}$ which provided a 10 fold higher signal than the blank sample. Samples were stored at $-70^{\circ}$ with one freeze/thaw cycle performed before GLP-1 measurement. We have found excellent freeze/thaw stability of GLP-1 in human plasma samples. Detection of GLP-1 after 1 to 4 freeze/thaw cycles in probes from 3 different individuals yielded an intra-assay variability of $9,23 \%$ which is comparable to the general intra-assay variability. To further validate the assay we performed mixing and spiking experiments. The mixture of equal amounts of two different plasma samples performed for 3 different pairs of samples provided a mean recovery of $93 \%$ of the expected GLP-1 concentration. Spiking experiments of 5, 10, 50, 100 and $500 \mathrm{pM}$ standards to a known plasma sample provided a mean recovery of $91 \%$ of the expected concentration.

\section{Statistics}

A multiple logistic regression model based on complete cases was used where the effect of GLP1 is adjusted for age, sex, BMI, hypertension, diabetes, smoking, LDL, CRP, GFR and triglycerides. Fractional polynomials were used
Table 1 Values are presented as $\mathbf{n}$ or median (interquartile range)

\begin{tabular}{lc}
\hline Characteristics & $\mathbf{n = 3 0 3}$ \\
\hline Age (yrs) & $63(55-70)$ \\
Sex & \\
$\quad$ Male & 202 \\
$\quad$ Female & 101
\end{tabular}

Body mass index $\left(\mathrm{kg} / \mathrm{m}^{2}\right)$

$26.2(24.1-29.0)$

Hypertension $^{*}$

Yes

147

No

126

Diabetes mellitus*

Yes

20

No

Smoker ${ }^{\dagger}$

Yes

42

No

230

Family history of $C A D^{+}$

Yes

77

No

195

Laboratory profile

LDL-cholesterol (mg/dl)

$122(95-149)$

HDL-cholesterol (mg/dl)

$52(44-59)$

Triglycerides (mg/dl)

143 (106-207)

High-sensitivity CRP (mg/dl)

$0.23(0.05-0.54)$

TNFa (pg/ml)

6,3 (4.5-7.9)

eGFR (ml/min)

$71(63-80)$

IL6 (pg/ml)

$0(0-3.2)$

GLP-1 (pM)

$2.9(1.5-4.9)$

Medical treatment ${ }^{\ddagger}$

Statin

120

Aspirin, Plavix or Marcumar

170

Betablocker

173

ACE-I or ARB

138

Diuretics

87

Insulin or OAD

16

CT data

$\begin{array}{ll}\text { Pericardial adipose tissue volume }(\mathbf{m l})^{\S} & 190(132-259) \\ \text { Number of coronary artery plaques (total) } & 3(1-6) \text { (range 0-26) } \\ \text { Number of calcified plaques } & 1(0-3) \text { (range 0-22) } \\ \text { Number of mixed plaques } & 0(0-1) \text { (range 0-10) }\end{array}$

"History of diabetes and hypertension is known in 273 patients.

${ }^{+}$History of smoking and family history of CAD is known in 272 patients.

${ }^{\ddagger}$ Medication is known in 258 patients.

${ }^{5}$ Adequate image quality for evaluation of PAT volume was obtained in 287 patients.

"Adequate image quality for evaluation of coronary plaques was obtained in 281 patients. 
for evaluating non-linear relationships between continuous covariates and the logarithmic odds for plaques. Further, generalized variance inflation (gVIF) factors were used for evaluating the presence of multicollinearity. A gVIF greater than 4.0 is usually indicates substantial multicollinearity. As a result of the multiple logistic regression model, odds ratios with corresponding 95\% confidence intervals and pvalues (two-sided) are reported. A p-value of lower than 0.05 is considered statistically significant. To evaluate the relationship between GLP1 and triglyceride and between GLP1 and eGFR, linear regressions based on complete cases with each variable transformed by the natural logarithm were used and the regression coefficients are reported. All statistical analyses were performed by using the statistical software $\mathrm{R}$ (version 2.13.1).

\section{Results}

Levels of total GLP-1 are associated with coronary plaque burden in humans

Serum concentrations of GLP-1 were assessed in a cohort of 303 patients undergoing coronary artery CT angiography due to typical or atypical chest pain. Baseline characteristics of the study have been published previously and are presented in Table 1 [11]. Briefly, the mean age of the study population was 63 years, 33\% were female, the body mass index was $26.2 \mathrm{~kg} / \mathrm{m}^{2}$, hypertension was present in $48 \%$, family history of coronary artery disease (CAD) in $25 \%, 7.2 \%$ were smokers and $7 \%$ had diabetes. The mean amount of coronary plaque burden detected by CT angiography was 3 (range 0 to 26) with no coronary plaques being detectable in 60 patients. Median GLP-1 in random non-fasting serum samples was 2.9 pM (IQR: 1.5-4.9). Using spearman association GLP-1 (log scale) was found to positively correlate with serum triglycerides (log scale) (Rho: 0.27 ; $\mathrm{p}<0.0001$ ), while a weak negative correlation was found with kidney function as defined by eGFR (estimate glomerular filtration rate; log scale) (RHO: -0.14; $\mathrm{p}<0.05$ ). Additional regression beta analysis for these two parameters found a statistically significant relationship between GLP-1 and triglycerides (regression coefficient: 0.35 (95\% confidence interval: $0.18-0.52$ ) ) and a nearsignificant relationship between GLP1 and eGFR (regression coefficient: -0.38 (95\% confidence interval: -0.77-0.01)). No obvious correlation was detected with other cardiovascular risk factors in the total cohort.

Within the framework of the multiple logistic regression model, non-linear relationships were detected for GLP1, CRP, triglyceride and GFR. For these four variables each non-linearity is best modeled by taking the natural logarithm of GLP1, CRP, triglycerides and eGFR. Besides, the maximum of the observed generalized variance inflation factors was 2.08 for age which indicates the absence of serious multicollinearity problems. The multiple logistic regression model revealed that the logarithm of GLP-1 was significantly associated with total coronary plaque burden in a model adjusted for age, sex, BMI, hypertension, diabetes, smoking, LDL, log. CRP, log. eGFR and log. triglycerides (OR: 2.53; 95\% CI: 1.12-6.08; p=0.03) (Table 2). The unadjusted OR for GLP-1 with total coronary plaque burden was 2.12 (95\% CI: 1.15-4.08; $\mathrm{p}=0.02$ ).

\section{Discussion}

In this study we found a positive association between GLP-1 serum levels and coronary artery disease in humans. This observation seems surprising taking the vasoprotective efficacy described for GLP-1 and its analogues in experimental models which seem to be confirmed by early clinical observations $[4,12]$. Furthermore, inhibition of DPP-4 dependent degradation of GLP-1 was found to reduce atherogenesis and increase plaque stability in mice while preliminary clinical data suggest similar vasoprotective efficacy in humans $[13,14]$. Nevertheless, others have reported GLP-1 serum levels to be increased in patients with high cardiovascular risk due to accumulation of components of the metabolic syndrome and type 2 diabetic subjects $[9,10]$. Our study confirms the previously described positive association between GLP-1 serum levels and serum triglycerides [10]. Increased GLP-1 concentrations in states of metabolic risk like hypertriglyceridemia could represent a counter regulation to increase insulin secretion in states of insulin resistance. Consistently, GLP-1 serum concentrations were recently found to be increased in type 2 diabetic patients [9]. Still long term treatment with GLP1 analogues significantly improved glycemic control and

Table 2 Multivariate Association of GLP-1 and relevant cardiovascular risk factors with total plaque burden as assessed by CT-angiography

\begin{tabular}{lcc}
\hline Variables & Total plaque & $\boldsymbol{p}$ \\
\hline OR $(\mathbf{C l})$ & $\mathbf{0 . 0 3}$ \\
Age & $2.53(1.12-6.08)$ & $<\mathbf{0 . 0 0 1}$ \\
Sex & $1.15(1.10-1.22)$ & $<\mathbf{0 . 0 0 1}$ \\
BMl & $13.92(4.47-51.53)$ & $\mathbf{0 . 0 1}$ \\
Hypertension & $1.20(1.05-1.39)$ & 0.98 \\
Diabetes & $1.01(0.38-2.65)$ & 0.36 \\
Smoking & $2.11(0.47-12.42)$ & $\mathbf{0 . 0 3}$ \\
LDL & $6.04(1.37-35.42)$ & 0.80 \\
log CRP & $1.00(0.99-1.01)$ & 0.78 \\
log TG & $1.15(0.45-3.18)$ & 0.18 \\
log eGFR & $2.22(0.71-7.41)$ & 0.92 \\
\hline
\end{tabular}

Odds ratio and $95 \% \mathrm{Cl}$ increase in plaque quantity for $1 \mathrm{pM}$ of total GLP-1 raise in plasma levels are presented.

Abbreviations: $L D L$ (low density cholesterol), CRP (hsCRP), TG (triglyceride), eGFR (estimate glomerular filtration rate), log. Logarithmic.

Bold numbers indicate significant associations with $\mathrm{p}<0.05$. 
produced meaningful weight loss as a major cardiovascular risk factor in type 2 diabetic patients $[15,16]$. In addition, GLP-1 analogues were found to be noninferior to metformin treatment in respect to circulating markers of inflammation, oxidative stress and vascular function in a 3 month lasting clinical trail [17] while protective effects of GLP-1 analogues were found in hepatocytes under ischemic stress [18].

GLP-1 is produced from intestinal L-cells from the epithelial layer of the gut mucosa in response to food ingestion, parasympatic nervous activation and endocrine mediators [5]. In addition IL6 as an inflammatory cytokine was recently found to increase GLP-1 secretion under in vitro and in vivo conditions [19]. Coronary atherosclerosis is a chronic inflammatory disease process which has been associated with IL6 [20]. We were however unable to detect associations between GLP-1 and different mediators of inflammation including IL6 in our population, making this an unlikely explanation.

Elimination of GLP-1 primarily depends on the kidney with increased circulating concentrations of GLP-1 being found in patients with chronic kidney disease and renal failure $[21,22]$. Consistently we found weak negative associations of GLP-1 with kidney function in our population. Chronic kidney disease is a major cardiovascular risk factor. Nevertheless associations of GLP-1 and atherosclerotic plaque burden remained significant after adjustment for kidney function, making impaired GLP-1 elimination in states of renal disease an unlikely explanation for the observed association of GLP-1 with coronary artery disease.

\section{Study limitations}

Our study holds several strength and limitations. This is the first study to establish a link between circulating serum concentrations of GLP-1 and coronary artery disease. This association remained significant in a fully adjusted model after consideration of age, sex, BMI, hypertension, diabetes mellitus, smoking, triglycerides, LDL-C, hsCRP, and eGFR. However as this was an association study, this does not establish a causal relationship between GLP-1 and coronary artery disease. Consequently, clinical implications of this observation still need to be established. Experimental data suggest vasoprotective efficacy of GLP-1, GLP-1 analoga and DPP-4 inhibition [4] which are supported by preliminary clinical data $[12,13]$. The observed increase of GLP-1 in context of vascular disease might therefore represent a counter regulatory attempt to limit disease progression. Increased GLP-1 secretion in states of metabolic disease might however also contribute to hyperinsulinemia which has been linked with vascular disease [2].

The GLP-1 assay used in this study does detect active GLP-1 in addition to processed metabolites of GLP-1. These GLP-1 metabolites might hold own vascular actions which seem to be mediated independent of the GLP-1 receptor [23]. Additional studies are needed to further discriminate associations between active GLP-1and its metabolites with cardiovascular disease. Furthermore, systemic and coronary artery concentrations of active GLP-1 might differ due to myocardial DPP-4 activity.

Serum samples in our study were collected randomly independent of the last food intake. As food ingestion is a strong stimulus of GLP-1 secretion this might have affected the observed associations [6]. Additional studies are needed to establish whether a similar link can be found under fasting conditions. Non-fasting conditions might however hold predictive relevance for some metabolic biomarkers. This has earlier been reported for serum triglycerides which better predicted cardiovascular risk when assessed in a non-fasting state [24].

Finally, our study results may only be applicable to nondiabetic patients as diabetic patients were clearly underrepresented in the present study ( $7 \%$ of the patients).

Additional investigations in larger cohorts are needed to further explore the association between GLP-1 and cardiovascular disease in larger cohorts under consideration of clinical outcome data.

In summary we found a surprising association of circulating GLP-1 with coronary atherosclerosis in humans. This might represent a contra-regulatory response in states of increased metabolic risk which warrants further investigations.

\section{Abbreviations}

ACE-I: Angiotensin-converting enzyme inhibitors; AHA: American Heart Association; ARB: Angiotensin II receptor blocker; BMI: Body mass index; CAD: Coronary artery disease; DPP-4: Dipeptidyl peptidase-4; eGFR: Estimate glomerular filtration rate; GLP-1: Glucagon-like peptide 1; HDL-C: High density lipoprotein cholesterol; hsCRP: High-sensitive C-reactive protein; IL6: Interleukin 6; LDL-C: Low density lipoprotein cholesterol; PAT: Pericardial adipose tissue; TNFa: Tumor necrosis factor alpha.

Competing interests

The authors declare that they have no competing interests.

\section{Authors' contributions}

$\mathrm{KP}$ : sample analysis and primary drafting of the manuscript; MB, JZ, IBF and GS: sample analysis; MG, AWL and AB: sample collection and CT analysis; RPL: statistical analysis; CL: sample collection and manuscript drafting; BG, NM and KGP: manuscript drafting; ML: study design and analysis, final manuscript drafting. All authors read and approved the final manuscript.

\section{Acknowledgments}

This work was supported by the Amylin Paul Langerhans Grant from the European Foundation for the Study of Diabetes (EFSD) and the German Research Foundation (DFG).

\section{Author details}

'Department of Internal Medicine I, University Hospital Aachen, Pauwelsstraße 30, 52074, Aachen, Germany. ${ }^{2}$ Department of Internal Medicine II, Ludwig-Maximilians University Munich, Munich, Germany. ${ }^{3}$ Department of Internal Medicine I, Ludwig-Maximilians University Munich, Munich, Germany. ${ }^{4}$ Institute of Medical Informatics, Biometry and Epidemiology, Ludwig-Maximilians University Munich, Munich, Germany. 
Received: 29 July 2013 Accepted: 30 July 2013

Published: 16 August 2013

\section{References}

1. Seshasai SR, Kaptoge S, Thompson A, Di Angelantonio E, Gao P, Sarwar N, Whincup PH, Mukamal KJ, Gillum RF, Holme I, et al: Diabetes mellitus, fasting glucose, and risk of cause-specific death. N Engl J Med 2011, 364 (9):829-841.

2. Bonora E, Formentini G, Calcaterra F, Lombardi S, Marini F, Zenari L, Saggiani F, Poli M, Perbellini S, Raffaelli A, et al: HOMA-estimated insulin resistance is an independent predictor of cardiovascular disease in type 2 diabetic subjects: prospective data from the Verona Diabetes Complications Study. Diabetes Care 2002, 25(7):1135-1141.

3. Boussageon $R$, Bejan-Angoulvant $T$, Saadatian-Elahi M, Lafont $S_{\text {, }}$ Bergeonneau C, Kassai B, Erpeldinger S, Wright JM, Gueyffier F, Cornu C: Effect of intensive glucose lowering treatment on all cause mortality, cardiovascular death, and microvascular events in type 2 diabetes: metaanalysis of randomised controlled trials. BMJ 2011, 343:d4169.

4. Lehrke M, Marx N: Cardiovascular effects of incretin-based therapies. Rev Diabet Stud 2011, 8(3):382-391.

5. Baggio LL, Drucker DJ: Biology of incretins: GLP-1 and GIP. Gastroenterology 2007, 132(6):2131-2157.

6. Vilsboll T, Krarup T, Deacon CF, Madsbad S, Holst JJ: Reduced postprandial concentrations of intact biologically active glucagon-like peptide 1 in type 2 diabetic patients. Diabetes 2001, 50(3):609-613.

7. Ranganath LR, Beety JM, Morgan LM, Wright JW, Howland R, Marks V: Attenuated GLP-1 secretion in obesity: cause or consequence? Gut 1996, 38(6):916-919.

8. Vaag AA, Holst JJ, Volund A, Beck-Nielsen HB: Gut incretin hormones in identical twins discordant for non-insulin-dependent diabetes mellitus (NIDDM)-evidence for decreased glucagon-like peptide 1 secretion during oral glucose ingestion in NIDDM twins. Eur J Endocrinol 1996 135(4):425-432

9. Calanna S, Christensen M, Holst JJ, Laferrere B, Gluud LL, Vilsboll T, Knop FK: Secretion of glucagon-like peptide- 1 in patients with type 2 diabetes mellitus: systematic review and meta-analyses of clinical studies. Diabetologia 2013, 56(5):965-972. doi:10.1007/s00125-013-2841-0. Epub 2013 Feb 3.

10. Yamaoka-Tojo M, Tojo T, Takahira N, Matsunaga A, Aoyama N, Masuda T, Izumi T: Elevated circulating levels of an incretin hormone, glucagon-like peptide-1, are associated with metabolic components in high-risk patients with cardiovascular disease. Cardiovasc Diabetol 2010, 9:17.

11. Broedl UC, Lebherz C, Lehrke M, Stark R, Greif M, Becker A, von Ziegler F, Tittus J, Reiser M, Becker C, et al: Low adiponectin levels are an independent predictor of mixed and non-calcified coronary atherosclerotic plaques. PLoS One 2009, 4(3):e4733.

12. Monami M, Cremasco F, Lamanna C, Colombi C, Desideri CM, lacomelli I, Marchionni N, Mannucci E: Glucagon-like peptide-1 receptor agonists and cardiovascular events: a meta-analysis of randomized clinical trials. Exp Diabetes Res 2011, 2011:215764.

13. Monami M, Ahren B, Dicembrini I, Mannucci E: Dipeptidyl peptidase-4 inhibitors and cardiovascular risk: a meta-analysis of randomized clinical trials. Diabetes Obes Metab 2013, 15(2):112-120.

14. Shah Z, Kampfrath T, Deiuliis JA, Zhong J, Pineda C, Ying Z, Xu X, Lu B, Moffatt-Bruce $S$, Durairaj $R$, et al: Long-term dipeptidyl-peptidase 4 inhibition reduces atherosclerosis and inflammation via effects on monocyte recruitment and chemotaxis. Circulation 2011, 124(21):2338-2349.

15. Fujishima Y, Maeda N, Inoue K, Kashine S, Nishizawa H, Hirata A, Kozawa J, Yasuda T, Okita K, Imagawa A, et al: Efficacy of liraglutide, a glucagon-like peptide-1 (GLP-1) analogue, on body weight, eating behavior, and glycemic control, in Japanese obese type 2 diabetes. Cardiovasc Diabetol 2012, 11:107.

16. Li CJ, Li J, Zhang QM, Lv L, Chen R, Lv CF, Yu P, Yu DM: Efficacy and safety comparison between liraglutide as add-on therapy to insulin and insulin dose-increase in Chinese subjects with poorly controlled type 2 diabetes and abdominal obesity. Cardiovasc Diabetol 2012, 11:142.

17. Kelly AS, Bergenstal RM, Gonzalez-Campoy JM, Katz H, Bank AJ: Effects of exenatide vs. metformin on endothelial function in obese patients with pre-diabetes: a randomized trial. Cardiovasc Diabetol 2012, 11:64.

18. Gupta NA, Kolachala VL, Jiang R, Abramowsky C, Romero R, Fifadara N, Anania F, Knechtle S, Kirk A: The glucagon-like peptide-1 receptor agonist
Exendin 4 has a protective role in ischemic injury of lean and steatotic liver by inhibiting cell death and stimulating lipolysis. Am J Pathol 2012, 181(5):1693-1701.

19. Ellingsgaard H, Hauselmann I, Schuler B, Habib AM, Baggio LL, Meier DT, Eppler E, Bouzakri K, Wueest S, Muller YD, et al: Interleukin- 6 enhances insulin secretion by increasing glucagon-like peptide- 1 secretion from $\mathrm{L}$ cells and alpha cells. Nat Med 2011, 17(11):1481-1489.

20. Panoulas VF, Stavropoulos-Kalinoglou A, Metsios GS, Smith JP, Milionis HJ, Douglas KM, Nightingale P, Kitas GD: Association of interleukin-6 (IL-6)$174 \mathrm{G} / \mathrm{C}$ gene polymorphism with cardiovascular disease in patients with rheumatoid arthritis: the role of obesity and smoking. Atherosclerosis 2009, 204(1):178-183.

21. Meier JJ, Nauck MA, Kranz D, Holst JJ, Deacon CF, Gaeckler D, Schmidt WE, Gallwitz B: Secretion, degradation, and elimination of glucagon-like peptide 1 and gastric inhibitory polypeptide in patients with chronic renal insufficiency and healthy control subjects. Diabetes 2004, 53(3):654-662

22. Orskov C, Andreasen J, Holst JJ: All products of proglucagon are elevated in plasma from uremic patients. J Clin Endocrinol Metab 1992, 74(2):379-384

23. Abu-Hamdah R, Rabiee A, Meneilly GS, Shannon RP, Andersen DK, Elahi D: Clinical review: The extrapancreatic effects of glucagon-like peptide-1 and related peptides. J Clin Endocrinol Metab 2009, 94(6):1843-1852.

24. Bansal S, Buring JE, Rifai N, Mora S, Sacks FM, Ridker PM: Fasting compared with nonfasting triglycerides and risk of cardiovascular events in women. JAMA 2007, 298(3):309-316.

doi:10.1186/1475-2840-12-117

Cite this article as: Piotrowski et al.: Circulating concentrations of GLP-1 are associated with coronary atherosclerosis in humans. Cardiovascular Diabetology 2013 12:117.

\section{Submit your next manuscript to BioMed Central and take full advantage of:}

- Convenient online submission

- Thorough peer review

- No space constraints or color figure charges

- Immediate publication on acceptance

- Inclusion in PubMed, CAS, Scopus and Google Scholar

- Research which is freely available for redistribution 